\title{
PENGARUH PENDIDIKAN DAN PELATIHAN TERHADAP KINERJA KARYAWAN PADA PT. PAL PLYWOOD BURAU CABANG PALOPO
}

\author{
GUNTUR SYAH, SRI WAHYUNI, MUH. YUSUF
}

\begin{abstract}
ABSTRAK
Penelitian ini bertujuan untuk mencari solusi dari permasalahan yang dikemukakan dipenelitian ini: untuk mengetahui dan menganalisis seberapa besar pengaruh Pendidikan dan Pelatihan kinerja karyawan bagi PT. PAL PLYWOOD Burau cabang Palopo.

Berdasarkan hasil penelitian ditemukan regresi berganda:

$b_{0}=4,445$

artinya konstanata sebesar 4,445 menyataakan bahwa variabel independen pendidikan dan pelatiahan dianggap konstan, maka rata-rata karyawan sebesar 4,445 .

$b_{1}=0,246$ pendidikan

menyatakan bahwa setiap penambahan pendidikan sebesar satu satuan akan meningkatkan kinerja karyawan.

$b_{2}=0,47$ pelatihan

menyatakaan bahwa setiap penambahan pelatihan akan meningkatkan kinerja karyawan sebesar 0,470.

Berdasarkan pokok permasalahan dapat ditarik kesimpulan: adanya pengaruh yang signifikan faktor-faktor variabel independen yaitu pendidikan dan pelatihan terhadap variabel dependen yaitu kerja karyawan. Berdasarkan hasil regresi linear berganda diketahui bahwa tingkat signifikan variabel pendidikan $(0,042)$ dan pelatihan $(0,000)$. Jadi hipotesis pada penelitian ini yang menduga bahwa faktor pendidikan dan pelatiahan berpengaruh terhdadap kinerja karyawan PT. Pal Plywood Burau cabang Palopo diterima dan terbukti kebenarannya.
\end{abstract}

Kata kunci:pendidikan, Pelatihan, Kinerja karyawan 


\section{Pendahuluan}

\section{Latar Belakang}

Perkembanga suatu Negara ditentukan oleh kemajuan dunia usaha di Negara tersebut, akan tetapi banyak ditentukan oleh kualitas SDM yang berperan sebagai perncana, melaksanakn dan mengendalikan organisasi yang bersangkutan seperti pada PT. PAL Plywood Burau cabang palopo.

Kontiunitas pembangunan yang dilakukan di Negara kita hanya dapat dipertahankn bila kualitas SDM memdapat perhatian dari pemerintah maupun dari kalngan swasta sebagai objek pembangunan. Dengan adanya pengembangn SDM dalam pemerintahan sangat tepat karena jumlah penduduk di Indonesia yang besar, yang merupakan sumber produktf potensial dapat memberikan kontribusi yang nyata pada suatu perusahaan yang diharapkan mampu membawa dampak positif terhadap perkembangan ekonomi dan perusahaan.

Mengacu pada fungsi-fungsi operatif diatas, maka diperlukan kajian pengembangan kualitas dari karyawan demi keberhasilan perusahaan, dan perlu diketahui bagaimana kedudukan personil dalam suatu unit kerja sehubungan dengan peningkatan kemampuan dan kacakapan karyawan. Masalah dalam penelitian ini adalah seberapa besar pengaruh pendidikan dan penelitian terhadap kerj karyawan pada PT. PAL PLYWOOD Burau cabang Palopo?. Tujuan penelitian untuk mengetahui dan menganalisis seberapa besar pengaruh Pendidikan dan Pelatihan kinerja karyawan bagi PT. PAL PLYWOOD Burau cabang Palopo.

\section{Metodologi Penelitian}

Lokasi dan Waktu Penelitian

Penelitian ini dilaksanakan di PT. PAL PLYWOOD Burau cabang Palopo Kabupaten Luwu Timur SUL-SEL.penelitian dilaksanakan pada tanggal 04 November 2011-29 Maret 2012.

Jenis dan Sumber Data

Data primer: data yang diperoleh secara langsung di PT. Pal plywood Burau untuk mengetahui keadaan di Lapangan yang sesungguhnya.

Data sekunder: data pendukung yang diperoleh dari berbagai pihak baik yang diperoleh dari berbagai pihak baik diperoleh langsung dari buku, dan literatur.

Populasi dan Sampel

Populasi dan sampel penelitian ini adalah seluruh karyawan pada PT. Pal Plywood Burau cabang palopo yang berjumlah 60 orang.

Metode Pengumpulan Data 
Metode pengumpulan data dalam penelitian ini adalah: (a) Oservasi (pengamatan), yaitu melakukan pengamatan secara langsung pada objek penelitian, (b) Interview (wawancara), yaitu mengadakan wawancara secara langsung dengan pimpinan perusahaan atau karyawan terkait untuk memperoleh data dan informasi.

Metode Analisis Data

Metode yang digunakan adalah regresi linear berganda:

$\mathrm{Y}=\mathrm{b}_{0}+\mathrm{b}_{1} \mathrm{X}_{1}+\mathrm{b}_{2} \mathrm{X}_{2}+\ldots \ldots \ldots \ldots . . \mathrm{e}$

Keteranagan $\mathrm{Y}=$ kinerja karyawan

$\mathrm{X}_{1}=$ pendidikan

$\mathrm{X}_{2}=$ standar error

$\mathrm{B}_{0}, \mathrm{~b}_{1}, \mathrm{~b}_{2}=$ variabel yang akan dicari.

\section{Hasil Persamaan Regresi}

\section{Hasil Penelitian Dan Pembahasan}

Tabel 10

Hasil Persamaan Regresi

\begin{tabular}{|c|c|c|c|c|c|}
\hline \multirow[t]{2}{*}{ Model } & \multicolumn{2}{|c|}{ Unstandardized Coefficients } & $\begin{array}{l}\text { Standardized } \\
\text { Coefficients }\end{array}$ & \multirow[b]{2}{*}{$\mathrm{t}$} & \multirow[b]{2}{*}{ Sig } \\
\hline & B & Std. Eror & Beta & & \\
\hline $1 \quad$ (Constant) & 4.455 & 1.961 & & 2.272 & .027 \\
\hline Pendidika & .246 & .119 & .264 & 2.076 & .042 \\
\hline pelatihan & .470 & .094 & .638 & .5 .010 & .000 \\
\hline
\end{tabular}

Dimana masing-masing regresi tersebut mempunyai arti:

$\mathrm{b}_{0}=4,445$

artinya konstanata sebesar 4,445 menyataakan bahwa variabel independen pendidikan dan pelatiahan dianggap konstan, maka rata-rata karyawan sebesar 4,445. $\mathrm{b}_{1}=0,246$ pendidikan

menyatakan bahwa setiap penambahan pendidikan sebesar satu satuan akan meningkatkan kinerja karyawan.

$\mathrm{b}_{2}=0,47$ pelatihan

menyatakaan bahwa setiap penambahan pelatihan akan meningkatkan kinerja karyawan sebesar 0,470 .

Analisis Koefisien Determinasi $\left(\mathbf{R}^{\mathbf{2}}\right)$

Koefisien Determinasi $\left(\mathrm{R}^{2}\right)$

\begin{tabular}{|l|l|l|l|l|}
\hline Model & & & $\begin{array}{l}\text { Adjusted R } \\
\text { Square }\end{array}$ & $\begin{array}{l}\text { Std. Eror Of } \\
\text { The Estimate }\end{array}$ \\
\hline 1 & $\mathrm{R}$ & R. Square & & .761 \\
\hline
\end{tabular}




\section{Pembahasan}

Pendidikan $\left(\mathrm{X}_{1}\right)$ dan pelatihan $\left(\mathrm{X}_{2}\right)$ mempunyai pengaruh yang signifikan terhadap variabel dependen yaitu kinerja karyawan (Y) sebesar 76,9\%. Dengan demikian dapat disimpulkan bahwa perubahan kinerja karyawan (Y) dipengaruhi oleh faktor lain dari variabel bebas pada penelitian ini sebesar $23,1 \%$.

Faktor pendidikan dan pelatihan memepunyai pengaruh signifikan terhadap variabel dependen yaitu kinerja karyawan menunjukkan bahwa asumsi pengabaian faktor-faktor lainnya, misalnya faktor disiplin.

Berdasrkan hasil regresi linear berganda diketahui bahwa tingkat signifikan variabel pendidikan $(X 1=0,042)$ dan penelitian $(X 2=0,000)$. Dengan demikian hipotesis pada penelitian ini yang menduga bahwa faktor pendidikan dan pelatihan berpengaruh terhadap kinerja karyawan PT. Pal Plywood Burau cabang Palapo diterima atau terbukti kebenarannya.

PT. Pal plywood Burau cabang Palopo akan memberiakan opini yang positif terhadap faktor pendidikan diantara pendidikan formal dan informal ditempuh sesuai dengan kebutuhan tugas, pendidikan yang ditempuh membuat mencapai target kerja yang ditetapkan PT. Pal Plywood Burau cabang Palopo, penyerapan materi yang dibebankan secara keseluruhan dalam pelaksanaan pendidikan sudah berjalan dengan baik, dengan pendidikan formal maka dapat bekerja dengan baik,. Faktor pelatihan mempunyai pengaruh positif signifikan sebesar $=47 \%$, artinya karyawan PT. Pal Plywood Buarau cabang Palopo sangat bermafaat, pelatihan yang diikuti selama bekerja menambah keterampilan dalam menjalankan tugas-tugas, menambah rasa percaya diri, setra mampu menghadapi tuntutan pekerjaan, jika dalam melaksanakaan pekerjaan dengan menggunakan alat, maka harus dikuasai dalam mengoperasinya.

Berdasarkan besarnya pengaruh faktor pendidikan dan pelatihan tersebut tehadap kinerja perusahaan, maka variabel pelatiahan memepunyai pengaruh dominan terhadap kinerja karyawan.

\section{Penutup}

Kesimpulan penelitian ini adalah bahwa adanya pengaruh yang signifikan faktor-faktor variabel independen yaitu pendidikan dan pelatihan terhadap variabel dependen yaitu kerja karyawan. Berdasarkan hasil regresi linear berganda diketahui bahwa tingkat signifikan variabel pendidikan $(0,042)$ dan pelatihan $(0,000)$. Jadi hipotesis pada penelitian ini yang menduga bahwa faktor pendidikan dan pelatiahan berpengaruh terhdadap kinerja karyawan PT. Pal Plywood Burau cabang Palopo diterima dan terbukti kebenarannya. Adapun saran dari penelitian untuk pimpinan PT. Pal Plywood Burau cabang Palopo bahwa adapun variabel-variabel yang mempengaruhi kinerja karyawan yaitu pendidikan dan pelatihan sudah memiliki efektivitas yang maksimal. 
Guntur Suyah et al - PENGARUH PENDIDIKAN DAN PELATIHAN TERHADAP KINERJA KARYAUAN PADA...

\section{Daftar Pustaka}

Prabu Mangkunegara,. 2000. Manajemen Sumber Daya Manusia. Yogyakarta

M. Manullang. 1998.Efektifitas Kerja Bagi pembangunan Negara. Yogyakarta

Google, Pendidikan dan Pelatiahan. Akses http//www.Pendidikn.co.id

Handoko T, Hani, 2000. Manajemen dan Sumber Daya Manusia. Edisi kedua. Yogyakarta: BPFE.

Soekidjo Notoadmojo. 1992. Manajemen Sumber Daya Manusia. Ganesa Bandung.

Google, UU Sisdiknas No. 20 Tahun 2003. Pendidikan.

Gomes (2003; 197). Pelatihan, Akses http//www.Pelatihan.co.id

Bernardin dan Russel, 1993 dalam As'ad 200. Kinerja Karyawan

H.Malayu SP. Hasibuan.2003. Manajemen Sumber Daya Manusia (Edisi Revisi)

Husein, Umar. 2003. Riset Sumber Daya Manusia Dalam Organisai. Jakarta: PT. Gramedia Pustaka Utama.

J.Supranto, 2001. Statistik Untuk Pemimpin Berwawasan Global. Salemba Empat.

Kustituanto, Bambang. 1994. Statistika I. Edisi pertama. Jakarta; Gunadarma

Mangkunegara AA, Anwar Prabu. 2002. Manajemen Sumber Daya Manusia Perusahaan. Bandung: Remaja Rosdakarya.

Notoadmojo Soekidjo. 1992. Pembangunan Sumber Daya Manusia. Jakarta: Ghalia Indonesia.

Norman Draper \& Harry Smith, Edisi kedua, 1992. Analisis Regresi terapan

Nur Indriantoro \& Supomo, Metodologi Penelitian Bisnis, BPFE-YOGYAKARTA, 1999. 